Editorial

\title{
Future Intelligent Systems and Networks
}

\author{
Carmen de-Pablos-Heredero \\ Research Groups Open Innova and Strategor, Department of Business Organization, Head of the Master Degree \\ and Doctoral Program in Business Organization and Master of Management of Strategic Logistic Processes, \\ SAP ERP Faculty of Social Sciences, Universidad Rey Juan Carlos, Office 15, Department Building, \\ 28032 Madrid, Spain; carmen.depablos@urjc.es; Tel.: +34-91-488-7545
}

Received: 23 August 2017; Accepted: 28 August 2017; Published: 2 September 2017

Keywords: digital divide; digital inequality; social stratification innovative business models; Internet Systems; networks; process innovation.

The purpose of this Special Issue is to collect current developments and future directions of Future Intelligent Systems and Networks. The motivation for this issue stems from the increasing interest of firms in applying technological possibilities to promote more innovative business models. The cases shown may become a real inspiration for firms to evolve to more innovative models by properly applying Intelligent Systems and Networks.

The first article, A Methodological Approach to Evaluate Livestock Innovations on Small-Scale Farms in Developing Countries authored by Antón García-Martínez, José Rivas-Rangel, Jaime Rangel-Quintos, José Antonio Espinosa, Cecilio Barba and Carmen de-Pablos-Heredero [1], analyses the knowledge of livestock innovations on small-scale farms in developing countries and confirms that implementing an intelligent system improves the viability of farms by an additional $21 \%$, due to a better integration of processes, resulting in more efficient management.

The second article, Turning Video Resource Management into Cloud Computing, authored by Weili Kou, Hui Li and Kailai Zhou [2], is focused on video resource management architecture based on The Hadoop Distributed File System (HDFS); it presents a design tested by establishing a simulation system prototype. It provides a uniform framework and a five-layer model for standardizing the current various algorithms and applications.

The third article, A Novel QoS Provisioning Algorithm for Optimal Multicast Routing in WMNs, authored by Weijun Yang and Yuanfeng Chen [3], is centered on optimal multicast routing in Wireless Mess Networks (WMNs) with Quality-of-Service (QoS) provisioning. Random static networks with different destination nodes are evaluated.

The fourth article, A Reliability Calculation Method for Web Service Composition Using Fuzzy Reasoning Colored Petri Nets and Its Application on Supercomputing Cloud Platform, authored by Ziyun Deng, Lei Chen, Tingqing He and Tao Meng [4], develops a Supercomputing Cloud Platform (SCP) prototype system using Service-Oriented Architecture (SOA) and Petri nets based on some technologies for Web service composition.

The fifth article, Socialism and the Blockchain, authored by Steve Huckle and Martin White [5], opens a discussion to present blockchain technologies as useful tools to enhance Socialist forms of governance.

The last article, A Novel Multi-Focus Image Fusion Method Based on Stochastic Coordinate Coding and Local Density Peaks Clustering, authored by Zhiqin Zhu, Guanqiu Qi, Yi Chai, and Yinong Chen [6], proposes a three-step novel stochastic model to coordinate a coding-based image fusion framework integrated with local density peaks. It offers some comparative experiments that demonstrate that fused images of the proposed method have higher qualities than existing state-of-the-art methods. 
Taken as a whole, these six papers highlight some useful applications and business models based on Internet Systems and Networks than can become an inspiration for firms operating in different industries.

\section{References}

1. García-Martínez, A.; Rivas-Rangel, J.; Rangel-Quintos, J.; Espinosa, J.A.; Barba, C.; de-Pablos-Heredero, C. A Methodological Approach to Evaluate Livestock Innovations on Small-Scale Farms in Developing Countries. Future Internet 2016, 8, 25. [CrossRef]

2. Kou, W.; Li, H.; Zhou, K. Turning Video Resource Management into Cloud Computing. Future Internet 2016, 8, 35. [CrossRef]

3. Yang, W.; Chen, Y. A Novel QoS Provisioning Algorithm for Optimal Multicast Routing in WMNs. Future Internet 2016, 8, 38. [CrossRef]

4. Deng, Z.; Chen, L.; He, T.; Meng, T. A Reliability Calculation Method for Web Service Composition Using Fuzzy Reasoning Colored Petri Nets and Its Application on Supercomputing Cloud Platform. Future Internet 2016, 8, 47. [CrossRef]

5. Huckle, S.; White, M. Socialism and the Blockchain. Future Internet 2016, 8, 49. [CrossRef]

6. Zhu, Z.; Qi, G.; Chai, Y.; Chen, Y. A Novel Multi-Focus Image Fusion Method Based on Stochastic Coordinate Coding and Local Density Peaks Clustering. Future Internet 2016, 8, 53. [CrossRef]

(C) 2017 by the author. Licensee MDPI, Basel, Switzerland. This article is an open access article distributed under the terms and conditions of the Creative Commons Attribution (CC BY) license (http:// creativecommons.org/licenses/by/4.0/). 